\title{
A CASE OF DEFICIENCY OF THE MALAR BONES WITH DEFECT OF THE LOWER LIDS
}

\author{
BY \\ 1. LlOyd JohNSTONE \\ WORCESTER
}

D.G., aged 14 years, was seen at the Guest Hospital and Eye Infirmary, Dudley, in March, 1942, presenting exactly the condition which was described by Miss Ida Mann, at the Oxford Ophthalmological Congress in July, 1942.

The patient was anxious to have his appearance improved and an operation was performed on the right eye. The normal outer

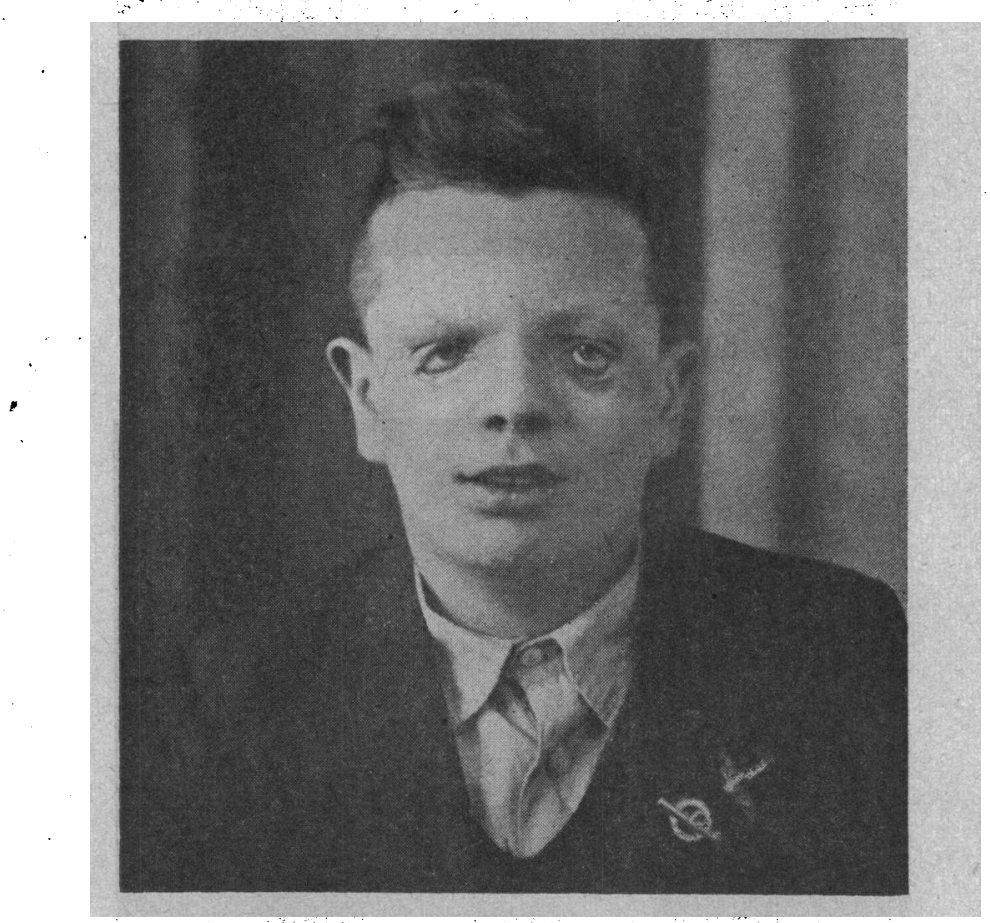

FIG. 1.

Left eye before operation. The notch and fibrous band between inner two thirds and outer third of lower lid are visible. The appearance is seen better if the right eye is covered.

third of the lower lid and triangle of tissue, including the fibrous band, was excised with the hope of raising the notch up to the outer canthus. Unfortunately the effect was to pull the upper eyelid down.

A second operation by sliding graft from the cheek was next done with the hope of relieving the tension and elevating the external canthus. This has given only slight improvement. 


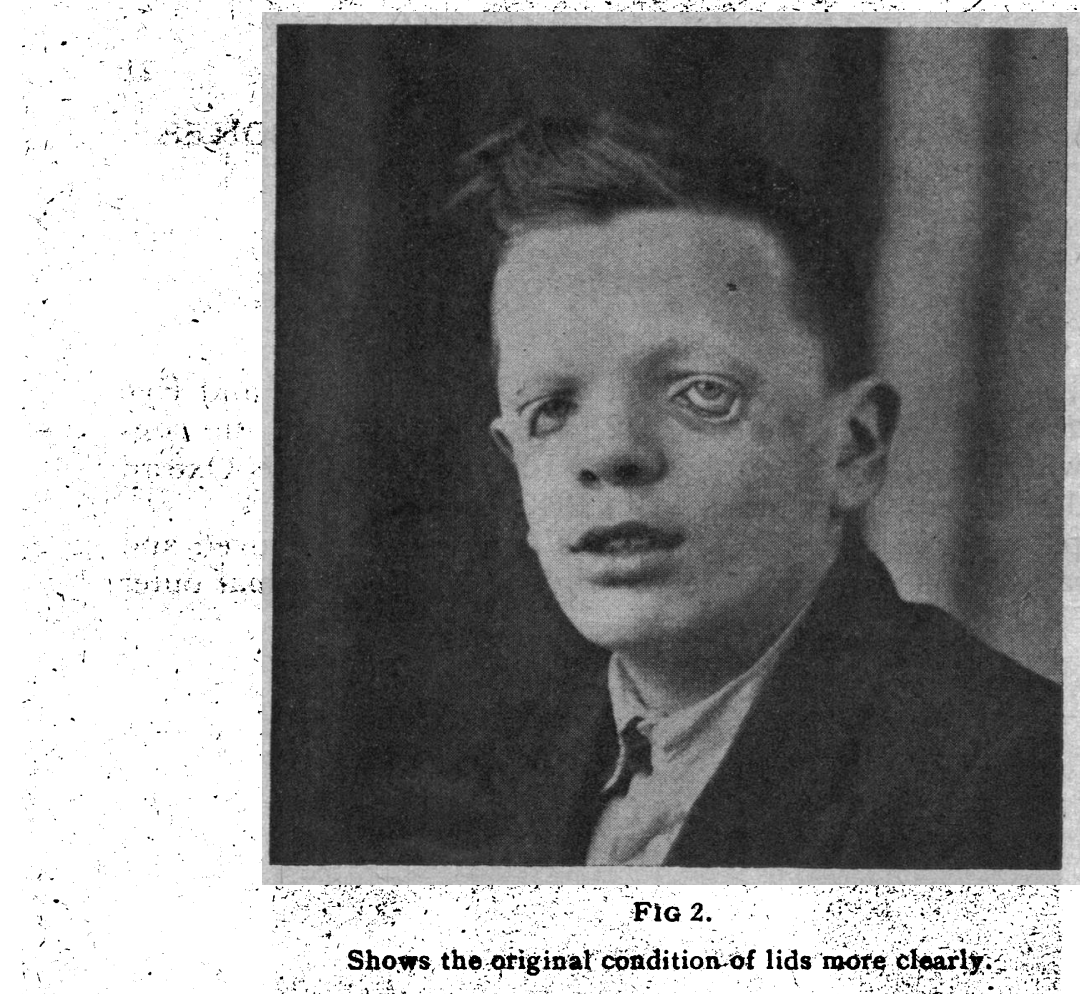

Shows the original condition of lids mote cloarly

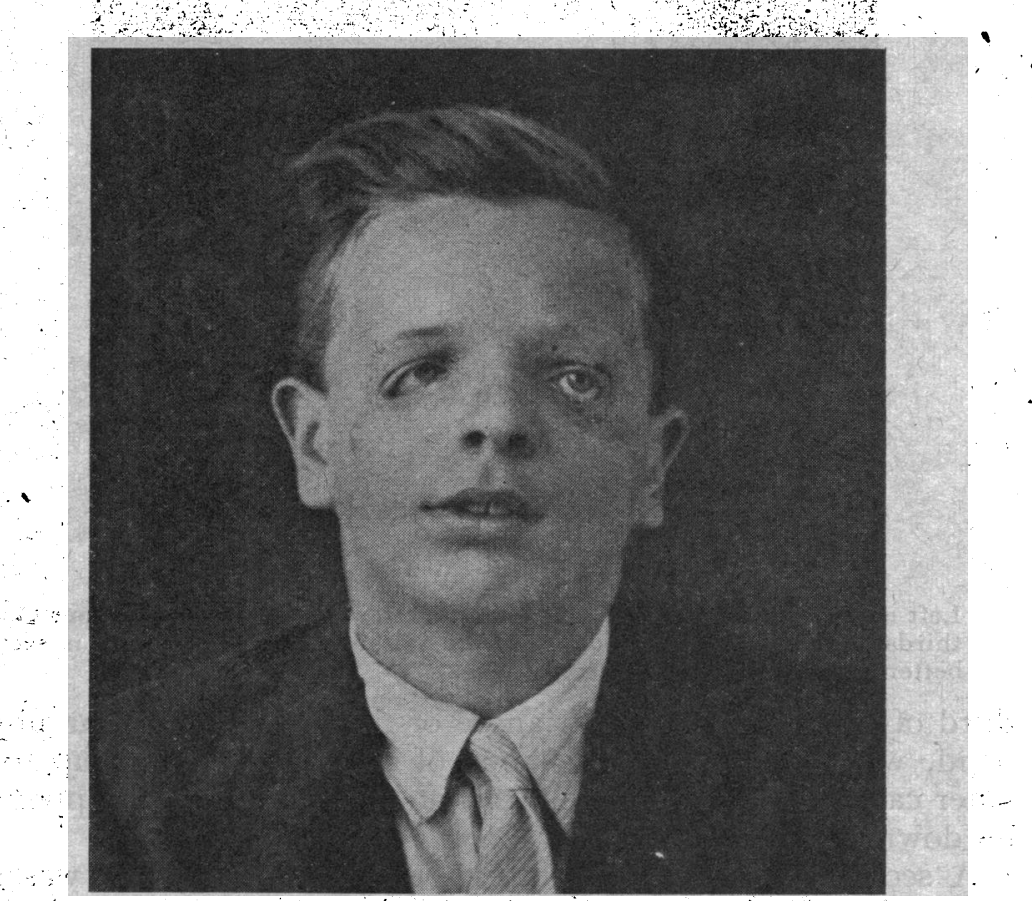

Fig. 3

Left eye after operation. Fibrous band excised and a pedicle graft from upper lid inserted in lower lid. 


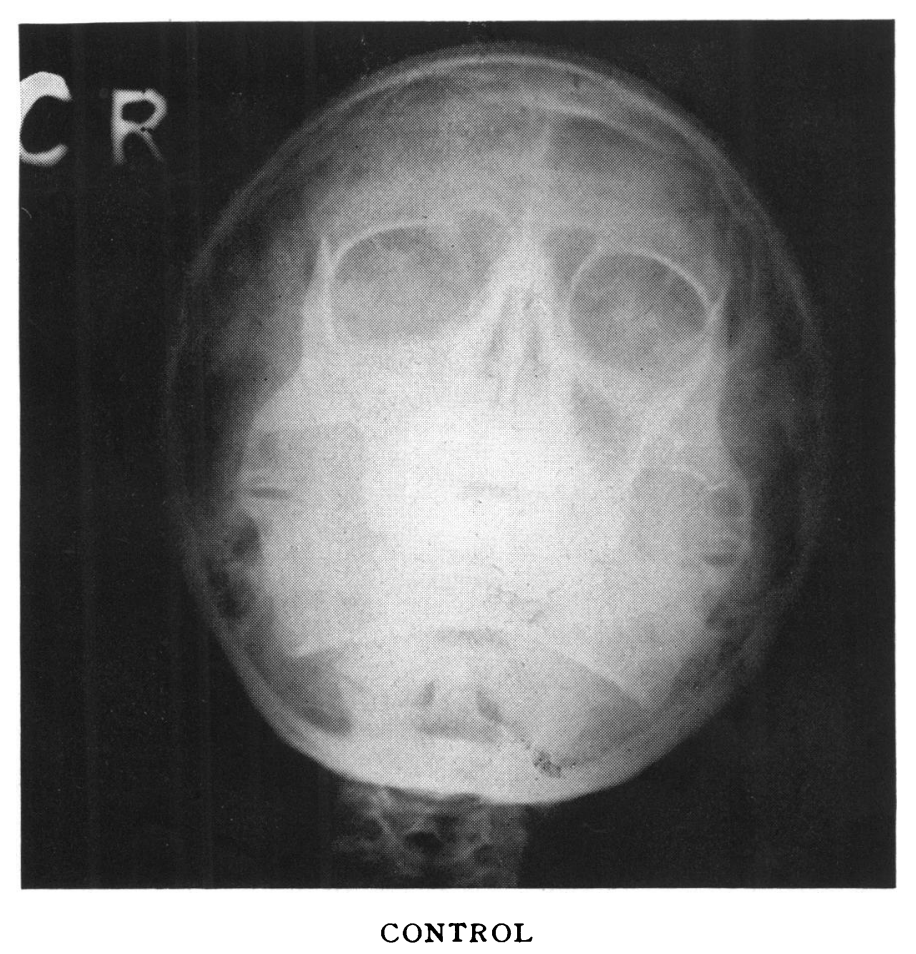


Manual elevation secures a very pleasing effect and it is proposed to do a fascia lata graft to complete the plastic repair by elevating the canthus.

The left eye was next operated on in June, 1942, this time by a pedicle graft from the upper lid inserted into the lower lid. The normal outer third of the lower lid with its eyelashes has not been removed, the fibrous band and notch only being excised. The result is fairly satisfactory and there seems no need in this case to resort to transplantation of cartilage.

This case seems ta be the least severe of the three cases under review.

1. am obliged to Dr. Alan Booth for the following report on the X-ray appearances:- "The zygomata of the patient are very poorly developed and can be seen to come to a point in the view of the base of the skull. The poor development is also seen in the "nose-chin' view."

\title{
UNILATERAL INVOL'VEMENT OF THE OPTIC NERVE IN HEAD INJURIES
}

\author{
BY \\ FREDERICK C. RODGER, M.B. \\ FROM THE TENNENT INSTITUTE OF OPHTTHAMOLOGY, \\ WESTERN INFIRMARY, GLASGOW
}

CASES of traumatic optic atrophy are to be found in every surgical ward. Those types of accident most frequently producing it are motor accidents; falls or blows on the head received in industry; and, in these days, war injuries; for example, blunt injuries sustained in air attacks from falling timber and masonry.

The lesion is uni-ocular and therefore prechiasmal.

The degree of violence may be so great that the patient suffers a fractured skull and lies unconscious for some weeks, or may be so slight that the patient is only momentarily dazed, with perhaps no external signs of violence at all. A remarkably simple injury was that in Praun's case in which optic atrophy resulted from a knock on the eyebrow with a potato!

Twenty-two patients were investigated by us in the Tennent Institute, but the records of two were omitted as one was complicated by a meningitis, the other by a positive Wassermann reaction. In some of the twenty cases remaining, the records were incomplete owing to the fact that an ophthalmic surgeon had not been summoned at an early period.

The clinical picture is a simple one. Soon after the accident each patient complained of a reduction of vision in one of his eyes. Seven of our cases were found to have no light perception; two had light perception only; three could count " fingers" at one 